\title{
Septoria Leaf Spot Reduces Flower Bud Set and Yield Potential of Rabbiteye and Southern Highbush Blueberries
}

\author{
P. S. Ojiambo, H. Scherm, and P. M. Brannen, Department of Plant Pathology, University of Georgia, Athens \\ 30602
}

\begin{abstract}
Ojiambo, P. S., Scherm, H., and Brannen, P. M. 2006. Septoria leaf spot reduces flower bud set and yield potential of rabbiteye and southern highbush blueberries. Plant Dis. 90:51-57.

In field trials on Premier rabbiteye blueberry, individual shoots were selected and tagged in the fall of 2001, 2002, and 2003 to quantify the effects of Septoria leaf spot severity and diseaseinduced premature defoliation on flower bud set and return yield. Experiments were carried out similarly on Bluecrisp southern highbush blueberry using shoots tagged after fruit harvest in the summer of 2002 and 2003. Leaves on the distal 20-cm segments of these shoots were monitored for disease severity (number of spots per leaf) through the remainder of the growing season; at the same time, defoliation (expressed as the proportion of nodes with missing leaves) was recorded for each of the shoot segments. Flower bud set was assessed subsequently in winter or early spring, and berries were harvested as they matured the following summer to determine return yield. For both cultivars, higher flower bud numbers were more likely to occur on shoots with lower disease levels the previous fall ( $P \leq 0.0462$ based on a Kolmogorov-Smirnov test). The data further showed that flower bud set potential (i.e., the maximum number of buds on shoots within a given disease severity range) decreased linearly as disease severity increased $\left(r^{2}\right.$ $\geq 0.926, P \leq 0.0005$ ). Based on the slope of this relationship, flower bud set potential decreased by one bud per shoot as disease severity the previous fall increased by 18 and 12 spots per leaf for Premier and Bluecrisp, respectively. Relationships between yield and disease variables were similar to those of flower bud numbers and disease, except that the decrease in yield potential (i.e., the maximum fruit weight per shoot within a given disease severity range) was less gradual than for flower bud set potential. On Premier, yield potential dropped markedly and significantly as disease severity the previous fall exceeded about 50 to 60 spots per leaf on average $(P<$ 0.0001 based on a Kruskal-Wallis test). Evidence for such a threshold effect was weaker on Bluecrisp, presumably because of the lower number of data points for this cultivar combined with lower yields due to poor pollination.
\end{abstract}

Additional keywords: Septoria albopunctata, Vaccinium ashei, V. corymbosum

Blueberry is the second most important commercial fruit crop in Georgia and currently is produced on more than 3,200 ha statewide (2). Among the different species of blueberry grown in the state, cultivars of the native rabbiteye blueberry (Vaccinium ashei) constitute about $90 \%$ of the production acreage, with the remaining $10 \%$ planted to the recently introduced, earlier-maturing southern highbush blueberry ( $V$. corymbosum interspecific hybrids) (29). According to a recent disease survey (28), both species can be affected by leaf spot diseases (3), of which Septoria leaf spot, caused by Septoria al-

Corresponding author: H. Scherm

E-mail: scherm@uga.edu

Funded in part by MBG Marketing, the Southern Region Small Fruit Consortium, and the USDACSREES Pest Management Alternatives Program (grant no. 01-34381-11181).

Accepted for publication 8 August 2005.

DOI: 10.1094/PD-90-0051

(c) 2006 The American Phytopathological Society bopunctata, is the most prevalent in Georgia (28) and other southeastern states (9). The disease is characterized by small circular leaf lesions with white to tan centers and purple margins (20). Most of the southern highbush and several rabbiteye blueberry cultivars are susceptible to Septoria leaf spot (28).

In Georgia, foliar symptoms of Septoria leaf spot first appear by early May, and disease severity increases rapidly after fruit harvest between June and September (22). High levels of disease during this period can lead to pronounced reductions in photosynthesis of affected leaves. Indeed, net assimilation rate of leaves in the field was reduced by approximately one-half at $20 \%$ disease severity, and values approached zero for leaves with $>50 \%$ necrotic leaf area (26). In addition, the disease can trigger premature defoliation during summer and early fall $(4,5,9,21)$. Premature defoliation of blueberry bushes in experiments with mechanical leaf removal resulted in lower yields in the subsequent growing season (36), presumably because defoliation reduced flower bud set during the fall by eliminating photoreceptors or lowering carbohydrate reserves during critical periods $(12,18)$.

Based on these considerations, it is likely that epidemics of Septoria leaf spot would reduce flower bud set and lower return yields by reducing photosynthesis of diseased leaves (26) or by causing premature defoliation (21). However, no studies have been conducted to determine the relationships among disease severity, defoliation, and reproductive development of blueberry. Therefore, the objective of this study was to quantify the effects of disease and disease-induced premature defoliation on flower bud set and return yield in field conditions.

\section{MATERIALS AND METHODS}

Field site and data collection. The study was carried out in an experimental rabbiteye blueberry planting at the University of Georgia Horticulture Farm near Athens (northeastern Georgia) from 200102 to 2003-04 (3 years), and in a commercial southern highbush blueberry planting near Homerville (southern Georgia) in 2002-03 and 2003-04 (2 years). The planting in Athens consisted of alternating rows of cvs. Premier and Climax to which no fungicides were applied throughout the study period. The planting in Homerville was part of a fungicide evaluation test $(4,5)$ and was composed of alternating rows of cvs. Bluecrisp and Star. Plants at both sites were mature, and maintenance of the plantings, including fertilization, pruning, and weed control, followed commercially recommended practices (1). Supplemental overhead irrigation was applied as needed.

On Premier, which is highly susceptible to Septoria leaf spot (28), 50 spring shoots (formed during the first flush of growth in the spring) were selected arbitrarily from 16 bushes in August or September 2001, 2002, and 2003; no shoots from later growth flushes during the summer and fall were included because little disease tended to develop on such shoots. Previous field studies $(21,22)$ documented minimal defoliation on spring shoots prior to late $\mathrm{Au}$ gust, followed by sustained increases in disease and defoliation thereafter. On Bluecrisp, which also is highly susceptible to the disease (28), 45 and 35 spring shoots were selected (one shoot per bush) about 1 month after fruit harvest in June 2002 and 2003, respectively. Each shoot was tagged $20 \mathrm{~cm}$ from its tip, and its height above the ground was measured to provide an indica- 
tion of shoot position within the canopy. Leaves on the distal $20 \mathrm{~cm}$ of these shoots were assessed individually at weekly to biweekly intervals for severity of Septoria leaf spot (expressed as number of spots per leaf), and a mean disease severity value was calculated for each shoot. On average, 10 to 13 leaves were present on each 20$\mathrm{cm}$ shoot segment. At the same time, defoliation (expressed as the proportion of nodes with missing leaves) was recorded for each of the shoot segments. On both cultivars, the last disease assessments were made in early to mid-November, after which leaf spots became difficult to count due to necrosis associated with natural leaf senescence. Shoots were monitored for defoliation for another 2 weeks after the last disease assessment date. Throughout the experimental period, Septoria leaf spot was the only noticeable foliar disease on the two cultivars used in the study.

Following each growing season, flower bud set and return yield were recorded in winter and spring to early summer, respectively. Flower bud set was determined by counting the number of flower buds on each of the tagged shoot segments in early February for Premier and in December or January for Bluecrisp. Fruit of Premier were harvested as they matured for a period of 2 to 4 weeks, starting in early June. Due to poor pollination that resulted in low fruit set of Bluecrisp in the 2002-03 trial, fruit were harvested only in the second year, in early May 2004. Fruit numbers and total fresh weights were determined for each tagged shoot segment, and yield was expressed as total fruit weight per shoot.

Data analysis. Disease severity and defoliation data summarized for each shoot segment were used to compute area under the disease progress curve (AUDPC, expressed as spot-days) and area under the defoliation progress curve (AUDefPC, expressed as proportion-days), respectively. Final disease severity for each shoot was calculated by averaging disease severity on the last assessment date prior to leaf abscission for all leaves on that shoot. Final disease severity, AUDPC, and AUDefPC were examined graphically to explore relationships with flower bud numbers and return yield.

A two-sample one-sided KolmogorovSmirnov test was used to evaluate whether higher flower bud numbers were more likely to occur on shoots with lower disease severity levels the previous fall. This was done by determining whether the cumulative frequency distributions of numbers of flower buds and numbers of shoots (both as functions of disease severity) were significantly different, based on the maximum vertical distance between the two distributions ( $D$-statistic). The corresponding $\chi^{2}$ and $P$ values were calculated in MS Excel 2002 (Microsoft, Redmond, WA) as described by Conover (10).

Additional analyses were carried with shoot segments grouped into seven disease severity classes, ranging from $<40$ to $>240$ and $<20$ to $>140$ spots per leaf for Premier and Bluecrisp, respectively. For each class, flower bud set potential was then defined as the maximum number of flower buds per shoot observed within that class. Linear regression analysis (PROC REG in SAS v. 8.2; SAS Institute Inc., Cary, NC) was used to relate flower bud set potential to the midpoint value of each disease severity class. Similar analyses were not carried out for return yield because there was no evidence for a steady decrease in yield potential (i.e., the maximum fruit weight per shoot observed within each disease severity class) as disease severity increased. Instead, for Premier, yield potential appeared to drop abruptly as disease severity exceeded about 60 spots per leaf on average (see below). To document this drop statistically, the distributions of return yields for shoots in two disease severity classes ( $<60$ and $\geq 60$ spots per leaf) were compared using the Kruskal-Wallis test (31), a nonparametric test of the null hypothesis that the distribution of a response is the same in multiple groups.

\section{RESULTS}

Disease severity and defoliation. No more than two tagged shoots were lost in any of the trials during the study period. Final disease severity in early to midNovember was generally higher on Pre- mier than on Bluecrisp (Table 1). On Premier, disease was most severe in 2002 (78.4 spots per leaf on average) and least severe in 2003 (40.0 spots per leaf). In contrast, disease severity on Bluecrisp was similar in 2002 and 2003. Trends in AUDPC and AUDefPC across years and cultivars followed those of disease severity, except that the lowest value of AUDefPC on Premier was observed in 2001 (Table 1).

Relationships between flower bud set and disease. The number of flower buds formed on each $20-\mathrm{cm}$ shoot segment ranged from 0 to 14 for Premier and 0 to 12 for Bluecrisp (Fig. 1). For both cultivars, plots of flower bud numbers versus final disease severity (Fig. 1A and B) revealed considerable scatter in the data. Specifically, whereas shoots with high disease levels always had low flower bud set, those having low disease levels had highly variable bud numbers. KolmogorovSmirnov tests revealed that the cumulative frequency distributions of numbers of flower buds and numbers of shoots in relation to disease severity (Fig. 2) were significantly different $\left(\chi^{2}=6.14, P=0.0462\right.$ and $\chi^{2}=6.53, P=0.0382$ for Premier and Bluecrisp, respectively), indicating that higher flower bud numbers were more likely to occur on shoots with lower disease severity.

Although the scatter in Figure 1A and B indicates that disease severity was a poor predictor of actual flower bud set, flower bud set potential (defined as the maximum number of buds on shoots with a given disease severity level) decreased linearly as disease severity increased (illustrated by the diagonal boundary lines in Figure 1A and $\mathrm{B}$ ). This trend was confirmed by histograms showing the maximum number of flower buds per shoot segment for different disease severity classes for the two cultivars (Fig. 3). When linear regression analysis was used to determine the relationship between maximum flower bud number per shoot $(y)$ and the midpoint values of the disease severity classes $(x)$, significant negative relationships were found for Premier $\left(y=13.8-0.058 x ; r^{2}=\right.$ $0.954, P=0.0002, n=156)$, and Bluecrisp

Table 1. Summary statistics of Septoria leaf spot-related variables on individual shoots of Premier rabbiteye and Bluecrisp southern highbush blueberry in field trials in Georgia from 2001-02 to 2003-04

\begin{tabular}{|c|c|c|c|c|c|c|c|}
\hline \multirow[b]{2}{*}{ Cultivar, year } & \multirow[b]{2}{*}{$n^{\mathbf{b}}$} & \multicolumn{2}{|c|}{$\begin{array}{c}\text { Final disease severity } \\
\text { (number of spots per leaf) }^{a}\end{array}$} & \multicolumn{2}{|c|}{$\begin{array}{l}\text { Area under the disease progress } \\
\text { curve (spot-days) }\end{array}$} & \multicolumn{2}{|c|}{$\begin{array}{l}\text { Area under the defoliation progress } \\
\text { curve (proportion-days) }\end{array}$} \\
\hline & & Mean & Range & Mean & Range & Mean & Range \\
\hline \multicolumn{8}{|l|}{ Premier } \\
\hline 2001-02 & 50 & 66.6 & $3.6-215.8$ & 1,655 & $66.3-4,411$ & 8.9 & $0-27.4$ \\
\hline $2002-03$ & 48 & 78.4 & $0.0-242.5$ & 2,578 & $0.0-8,917$ & 31.4 & $0-105.1$ \\
\hline 2003-04 & 48 & 40.0 & $3.8-117.0$ & 1,918 & $226.5-5,301$ & 20.3 & $0-59.6$ \\
\hline \multicolumn{8}{|l|}{ Bluecrisp } \\
\hline $2002-03$ & 43 & 20.4 & $1.5-117.5$ & 1,144 & $71.3-4,322$ & 16.5 & $0-70.1$ \\
\hline 2003-04 & 35 & 26.9 & $2.8-158.5$ & 1,125 & $220.1-4,443$ & 26.7 & $0-83.4$ \\
\hline
\end{tabular}

${ }^{a}$ Mean number of spots per leaf on the last assessment date prior to leaf abscission, averaged across all leaves per shoot segment.

${ }^{\mathrm{b}}$ Number of $20-\mathrm{cm}$ shoot segments used for assessment of disease variables, flower bud set, and return yield. Each shoot segment had an average of 10 to 13 leaves. 
( $y=11.5-0.084 x ; r^{2}=0.928, P=0.0005, n$ $=80$ ). Based on the slopes of the regression lines, flower bud set potential decreased by one bud per shoot as final disease severity increased by 18 and 12 spots per leaf for Premier and Bluecrisp, respectively.

Considerable scatter also was apparent in plots illustrating the relationship between numbers of flower buds per shoot segment and AUDPC or AUDefPC (Fig. 1C-F). However, as was the case with final disease severity, a negative trend was apparent between flower bud set potential and the two variables for both cultivars.

Relationships between return yield and disease. Fruit weight and number of fruit per shoot were strongly correlated in Premier $\left(r^{2}=0.939, P<0.0001, n=46\right)$ and Bluecrisp $\left(r^{2}=0.867, P<0.0001, n=\right.$ $33)$; therefore, only fruit weight data are presented here. Fruit yields of Premier ranged from 0 to $72.4 \mathrm{~g}$ per $20-\mathrm{cm}$ shoot segment and were highest in the 2001-02 trial (Fig. 4A, C, and E). In Bluecrisp, fruit yields were measured only in the 2003-04 trial and were compromised by low fruit set, the highest yield being only $9.3 \mathrm{~g}$ per shoot (Fig. 4B, D, and F). As was the case with the relationship between flower bud numbers and disease, considerable scatter was observed in plots of yield versus final disease severity, AUDPC, or AUDefPC. Nonetheless, the highest yields were ob-

Premier

Bluecrisp

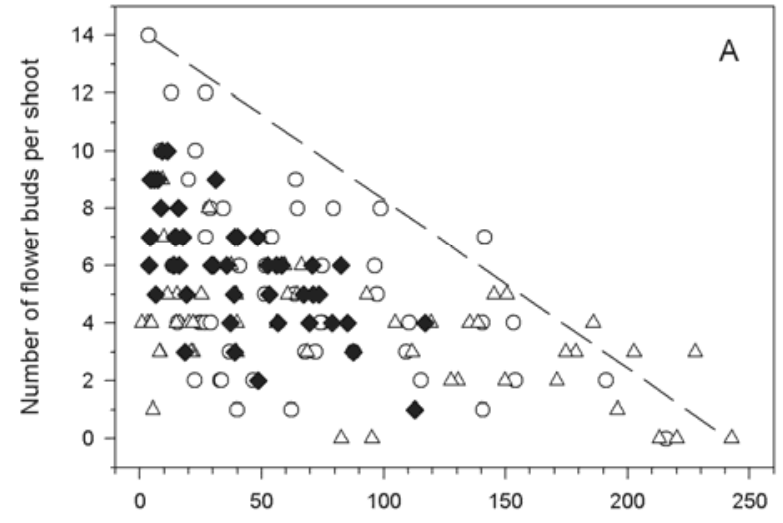

Final disease severity (number of spots per leaf)

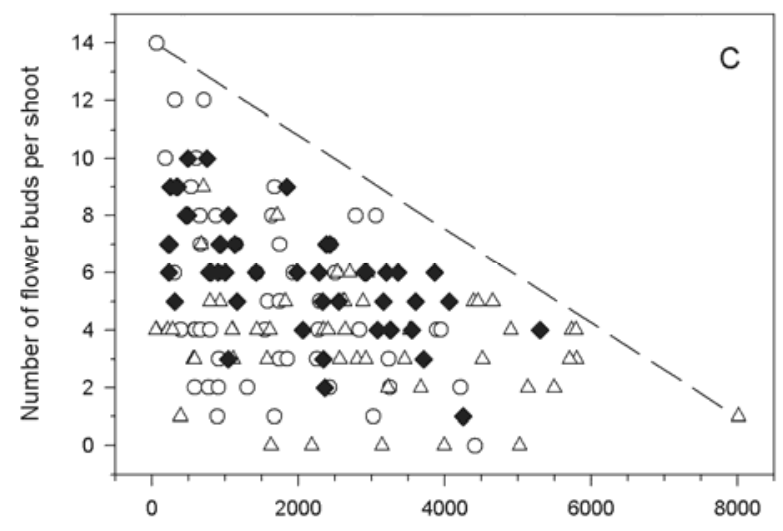

Area under the disease progress curve (spot-days)

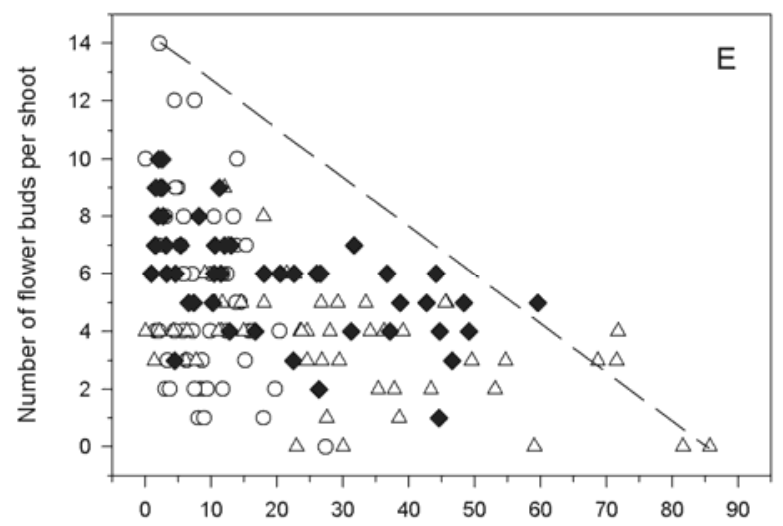

Area under the defoliation progress curve (proportion-days)

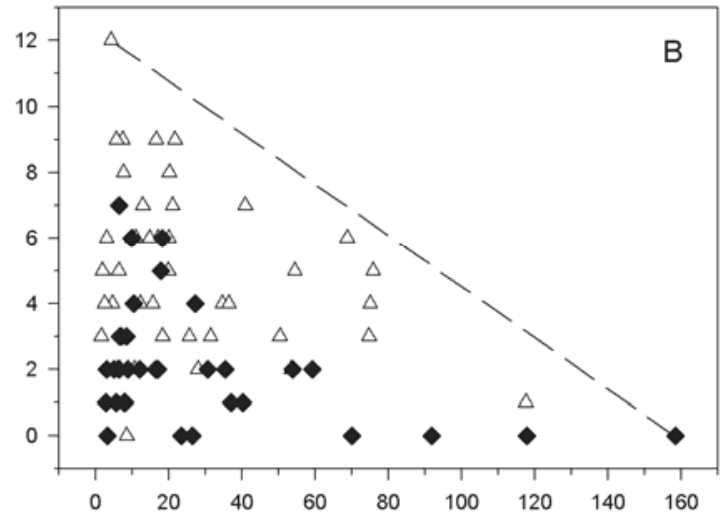

Final disease severity (number of spots per leaf)

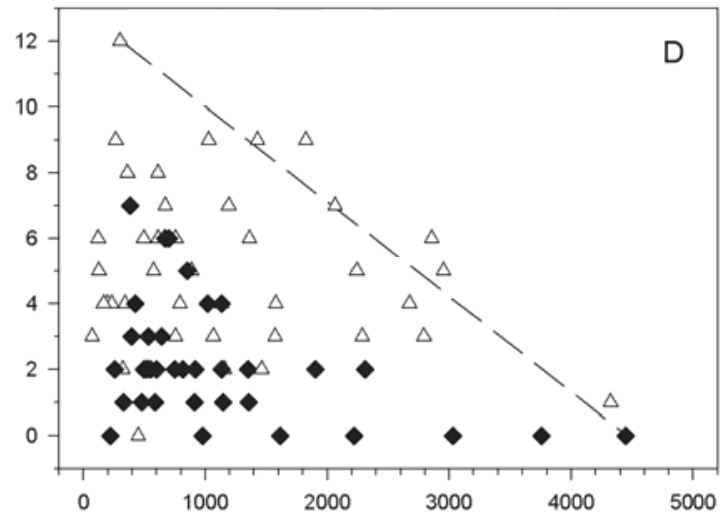

Area under the disease progress curve (spot-days)

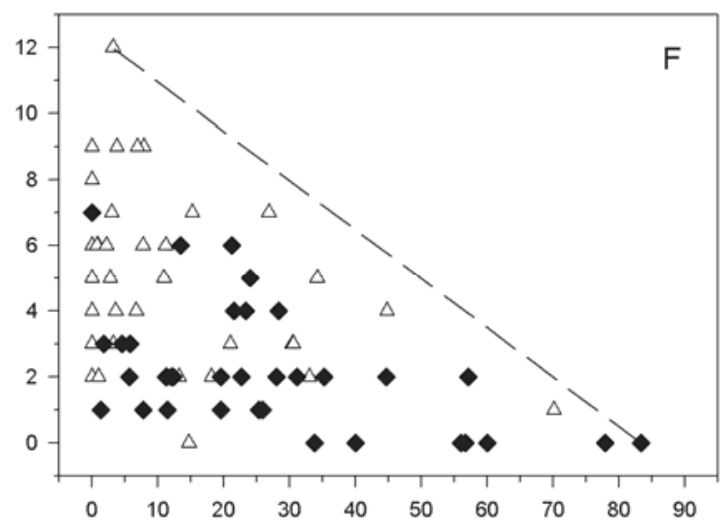

Area under the defoliation progress curve (proportion-days)

Fig. 1. Relationships between flower bud set and Septoria leaf spot-related variables on individual shoots of Premier rabbiteye and Bluecrisp southern highbush blueberry in field trials in Georgia in 2001-02 $(O), 2002-03(\Delta)$, and 2003-04 $(\bullet)$. A and B, Final disease severity (mean number of spots per leaf on the last assessment date prior to leaf abscission, averaged across all leaves per 20-cm shoot segment); $\mathbf{C}$ and $\mathbf{D}$, area under the disease progress curve; $\mathbf{E}$ and $\mathbf{F}$, area under the defoliation progress curve. The diagonal boundary lines, constructed by joining the points with the highest number of buds and the highest disease or defoliation level, may be interpreted as representing the decrease in flower bud set potential due to Septoria leaf spot. 
served at low disease or defoliation levels, whereas higher levels of the latter variables were associated consistently with shoots having the lowest yields.

On Premier, yield potential (i.e., the maximum yield at a given disease level) remained relatively unaffected by disease up to about 50 to 60 spots per leaf and then dropped markedly thereafter (Fig. 4A). Indeed, when shoots were grouped into two severity classes having $<60$ and $\geq 60$ spots per leaf on average, mean return yield was higher for the former class (19.1 g per 20-cm shoot segment) than for the latter (9.5 g) (Fig. 5). Based on the Kruskal-Wallis test, the distributions of final disease severity values among the two classes were significantly different $\left(\chi^{2}=\right.$ $18.5, P<0.0001)$. Due to the low number of data points, the evidence for a disease or defoliation threshold associated with an abrupt drop in yield potential was weaker in Bluecrisp (Fig. 4B, D, and F).

\section{DISCUSSION}

This is the first study to provide quantitative information about the effects of Sep- toria leaf spot severity and disease-induced defoliation on reproductive development in blueberry. Specifically, we document here the negative effect of epidemics in the summer and fall on subsequent flower bud set and return yield potential in rabbiteye and southern highbush blueberry. Previously, Cline (9) reported reductions in flower bud set and return yield of highbush blueberry affected by a complex of foliar diseases including Gloeosporium and Septoria leaf spots in North Carolina, but the relative contribution of the individual diseases could not be quantified.

The negative effects of Septoria leaf spot on flower bud set and return yield potential observed in the present study were likely due to a reduction in the photosynthetic capacity of affected leaves; directly, by reducing the leaf area available for photosynthesis and the photosynthetic capacity of the remaining green leaf area (26), and indirectly, by inducing premature defoliation (21). Similar effects of foliar diseases on return yield have been reported in other fruit crop pathosystems $(16,27,30,32)$. All these reports attribute reductions in return yield to reduced storage of carbohydrates $(8,23)$ or nitrogenous compounds $(24,34)$ in woody plant organs during autumnal senescence. These reserves play an important role in early growth of shoots and fruit during the following spring (17). In blueberry, defoliation in early fall also reduces the potential for transformation of axillary buds into flower buds by removing receptors of the short-day stimulus (18).

In both cultivars, plots of actual flower bud numbers or yield versus final disease severity showed considerable scatter, with some shoots having low flower bud numbers or yield despite having had leaves with low disease severity the previous fall. This variability, which was not reduced when integrated disease variables such as AUDPC or AUDefPC were used, should not be surprising, given that numerous biological and environmental factors $(6,12)$ in addition to disease can affect flower bud set and return yield. Even in annual crops, relationships between disease and yield are often weak due to the complex interactions among these factors $(33,35)$. In perennial
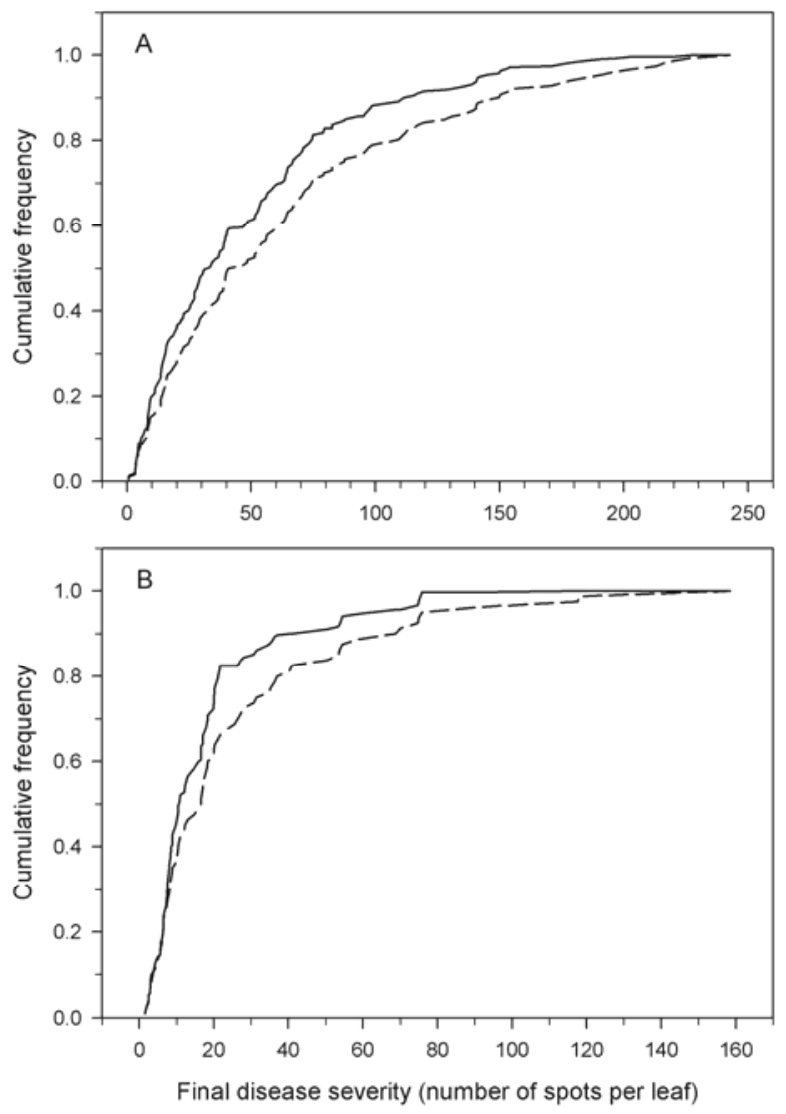

Fig. 2. Cumulative frequency distributions for numbers of flower buds per 20-cm shoot segment (solid lines) and number of shoot segments (dashed lines) in relation to final severity of Septoria leaf spot for A, Premier rabbiteye $(n=156)$ and $\mathbf{B}$, Bluecrisp southern highbush blueberry $(n=80)$. Final disease severity is defined as the mean number of spots per leaf on the last assessment date prior to leaf abscission, averaged across all leaves per 20-cm shoot segment. For both cultivars, a one-sided KolmogorovSmirnov test for the maximum vertical deviation between the two cumulative distributions ( $D$-statistic) indicated significant differences at $\alpha=0.05$, showing that higher flower bud numbers were more likely to occur on shoots with lower disease levels the previous fall.
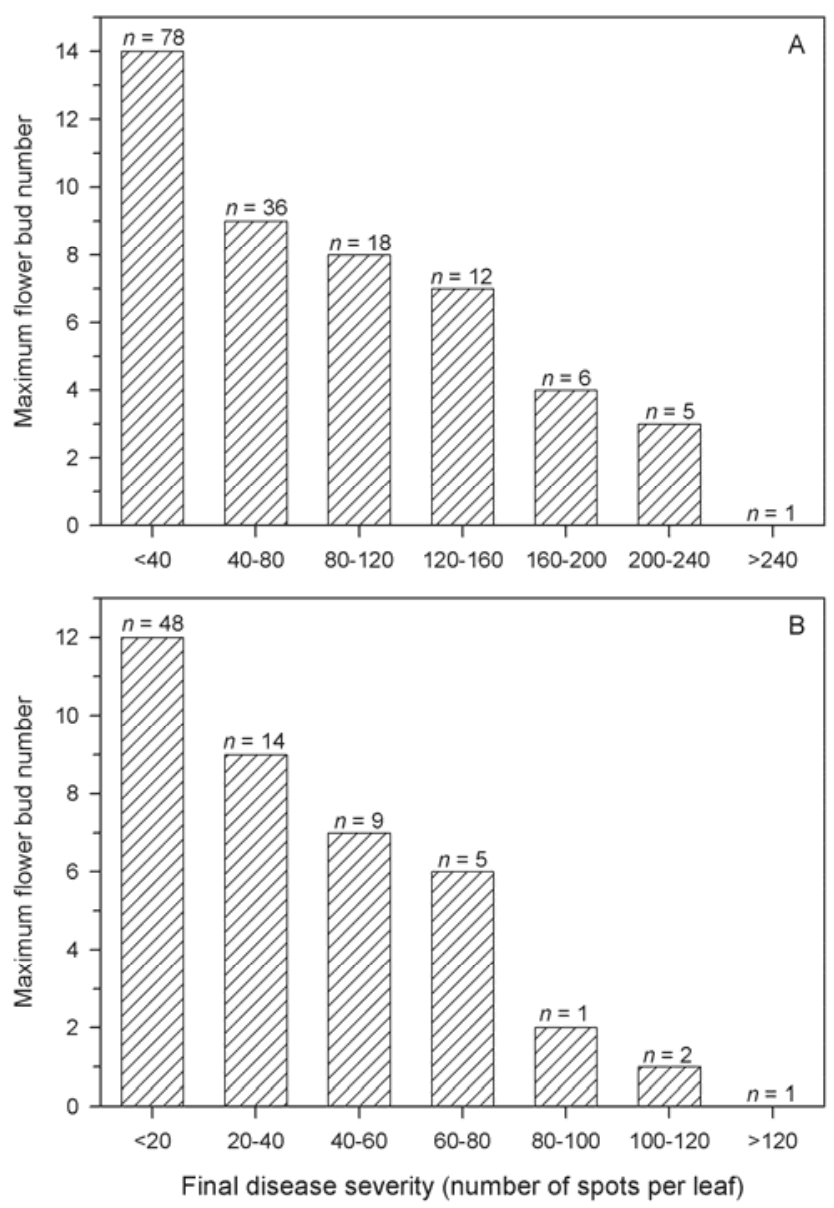

Fig. 3. Histograms showing the maximum number of flower buds per 20$\mathrm{cm}$ shoot segments of A, Premier rabbiteye and B, Bluecrisp southern highbush blueberry for different classes of final Septoria leaf spot severity in field trials in Georgia from A, 2001-02 to 2003-04 or B, 2002-03 to 2003-04. Final disease severity is defined as the mean number of spots per leaf on the last assessment date prior to leaf abscission, averaged across all leaves per 20 -cm shoot segment. The sample size, $n$, represents the number of shoots within each disease severity class. 
fruit crop pathosystems such as citrusgreasy spot (19), peach-rusty spot (14), apple-Marssonina coronaria (27), and coffee-leaf rust (6), factors such as nutritional status and biennial bearing pattern have been documented to complicate the relationship between disease and yield even further. In blueberry, reduced flower bud set and low yields on shoots with low levels of disease could be due to other shoot-related factors that affect carbohydrate supply (e.g., shoot position in the canopy, shoot orientation, or shoot diame- ter; 12,15). Although shoot orientation and diameter were not measured in the present study, we recorded heights of shoots above the ground as a surrogate for shoot position within the canopy. However, no significant correlation was observed between shoot height and flower bud numbers or yield (data not shown). Thus, differences in canopy position among shoots apparently were not large enough to be a confounding factor in the present study.

Despite the variability in the relationships between flower bud numbers or yield and disease, some useful patterns could be discerned. First, for flower bud set, higher flower bud numbers were significantly more likely to occur on shoots with lower disease levels the previous fall. In addition, there was a striking pattern for the maximum number of buds on shoots within a given disease severity range (interpreted as flower bud set potential) to decrease linearly as disease levels increased. This relationship (represented by the boundary lines in Figure 1 and the histograms in Figure 3) shows that the gap between flower bud set
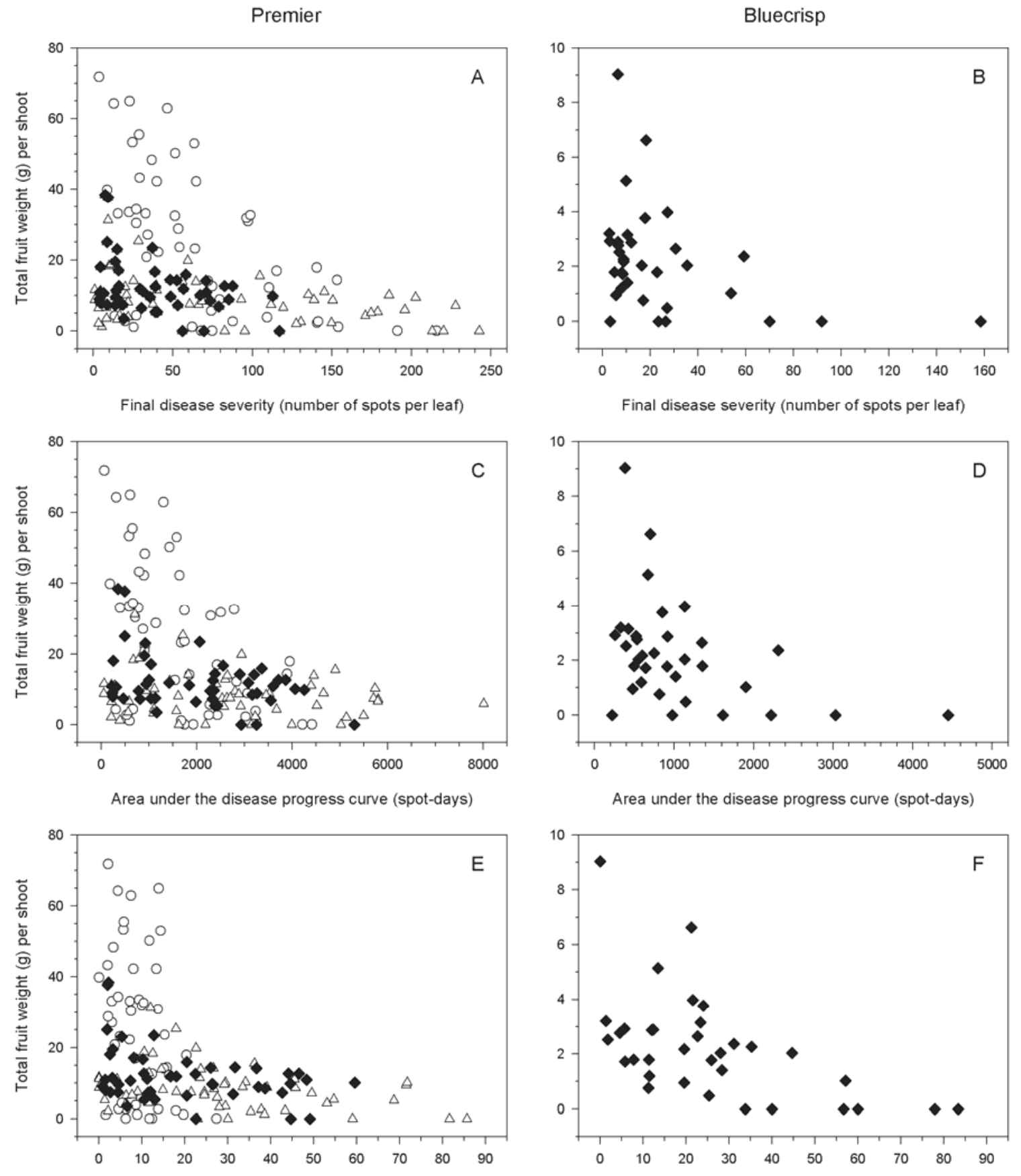

Area under the defoliation progress curve (proportion-days)

Area under the defoliation progress curve (proportion-days)

Fig. 4. Relationships between return yield and Septoria leaf spot-related variables on individual shoots of Premier rabbiteye and Bluecrisp southern highbush blueberry in field trials in Georgia in 2001-02 (O), 2002-03 ( $\triangle$ ), and 2003-04 ( $)$. A and B, Final disease severity (mean number of spots per leaf on the last assessment date prior to leaf abscission, averaged across all leaves per $20-\mathrm{cm}$ shoot segment); $\mathbf{C}$ and $\mathbf{D}$, area under the disease progress curve; $\mathbf{E}$ and $\mathbf{F}$, area under the defoliation progress curve. 
potential in the absence of Septoria leaf spot and bud set potential in the presence of the disease becomes progressively wider as disease severity increases. This gap may be interpreted as representing the contribution of Septoria leaf spot to reductions in flower bud number, whereas the scatter below the boundary lines in Figure 1 may indicate reductions due to other causes. For each additional leaf spot, reductions in flower bud set potential were greater for Bluecrisp than for Premier. This can be explained by the larger diameters of leaf spots on Bluecrisp compared with those on Premier (28). Thus, reductions in flower bud numbers are more likely to occur at lower leaf spot numbers for Bluecrisp than for Premier.

Relationships between yield and disease variables were similar to those between flower bud numbers and disease, except that the decrease in yield potential was less gradual than the decrease in flower bud set potential. On Premier, for example, there was evidence for a threshold effect, whereby yield potential dropped abruptly as final disease severity, AUDPC, and AUDefPC exceeded about 50 to 60 spots per leaf, 2,000 spot-days, and 20 proportion-days, respectively. Evidence for such a threshold effect was weaker on Bluecrisp, presumably due to the lower number of data points for this cultivar combined with the lower yields.

Part of our arguments concerning relationships among disease variables, flower bud set, and yield are based on a visual assessment of the patterns apparent in scatter plots and histograms of these variables. In general, patterns are defined as discontinuities in data exhibiting some measure of repetition (25). Recognition of such patterns can help in interpretation of data and development of new ideas (such as the concepts of flower bud set potential and yield potential per shoot in the present study) as well as in designing of follow-up experiments (25). Boundary lines to delineate patterns, such as those shown in Figure 1, have been used previously to develop soil nutrient norms for soybean production (13).

Further research is needed to explore the usefulness of the results observed in this study for making disease management decisions. First, one needs to remember that strong linear relationships were observed for potential flower bud set; relationships for actual flower bud numbers and yield were much more variable. Thus, further experiments are needed in an effort to explain the variability observed in this study. Second, the disease variables used in this study were based on season-long or end-of-season assessments, whereas management decisions need to be made earlier in the season. In many cases, however, yield loss assessments utilizing singlepoint disease measurements early in the season have failed to adequately explain the relationships between yield and disease severity in most pathosystems, including even annual crops where disease development and yield formation occur in the same season $(11,33,35)$. We currently are investigating the season-long temporal dynamics of Septoria leaf spot epidemics in blueberry and information generated from that study could be used to predict, early in the season, whether the disease thresholds indicated above will be exceeded.

Waggoner and Berger (35) proposed yield loss models based on a healthy leaf area index, which considered growth of the host, disease severity, and defoliation

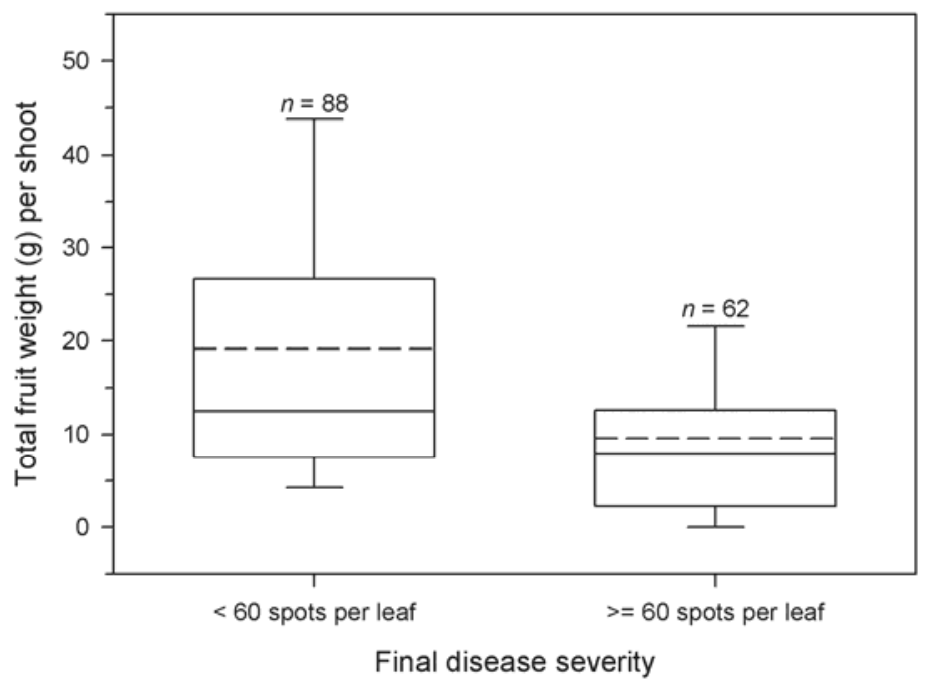

Fig. 5. Box-whisker plots showing the distribution of total fruit weight for individual shoots of Premier rabbiteye with different severity levels of Septoria leaf spot in field trials in Georgia from 2001-02 to 2003-04. Final disease severity is defined as the mean number of spots per leaf on the last assessment date prior to leaf abscission, averaged across all leaves per 20-cm shoot segment. The boxes represent the interquartile range, with the whiskers indicating the 5- and 95-percentiles. Solid and dashed lines within the boxes represent median and mean fruit weight, respectively.

throughout the season. Although green leaf area was not measured in our study, future studies in blueberry should consider utilizing this approach. Healthy leaf area indexbased models $(7,35)$ have been developed and tested for pathosystems where both disease and yield effects occur in the same growing season; it will be interesting to determine whether such models better describe the relationship between return yield and disease severity in the previous season, which is relevant not only for Septoria leaf spot of blueberry but also for other pathosystems involving perennial crops.

\section{ACKNOWLEDGMENTS}

We thank J. Vanerwegen for providing research plots at the Homerville site; A. Savelle for assistance in data collection; and F. Ferrandino, S. NeSmith, K. Stevenson, and A. Culbreath for useful comments on the manuscript.

\section{LITERATURE CITED}

1. Austin, M. E. 1994. Rabbiteye Blueberries: Development, Production, and Marketing. Agscience, Auburndale, FL.

2. Boatright, S., and McKissick, J. 2003. Georgia Farm Gate Value Report 2002. AR03-01, Center for Agri-Business and Economic Development, University of Georgia, Athens.

3. Brannen, P. M. 2001. Leaf spots of blueberry-How to identify and control them. Pages 18-19 in: Proc. Southeast. Blueberry Conf. Savannah, GA.

4. Brannen, P. M., Scherm, H., and Bruorton, M. D. 2002. Fungicidal control of Septoria leaf spot of blueberry, 2001. Fungic. Nematicide Tests 57:SMF46.

5. Brannen, P. M., Scherm, H., and Bruorton, M. D. 2003. Fungicidal control of Septoria leaf spot of blueberry, 2002. Fungic. Nematicide Tests 58:SMF019.

6. Brown, J. S., Whan, J. H., Kenny, M. K., and Merriman, P. R. 1995. The effect of coffee leaf rust on foliation and yield of coffee in Papua New Guinea. Crop Prot. 14:589-592.

7. Bryson, R. J., Paveley, N. D., Clark, W. S., Sylvester-Bradley, R., and Scott, R. K. 1997. Use of in-field measurements of green leaf area and incident radiation to estimate the effects of yellow rust epidemics on the yield of winter wheat. Eur. J. Agron. 7:53-62.

8. Choi, S. T., Park, D. S., Song, W. D., Kang, S. M., and Shon, G. M. 2003. Effect of different degrees of defoliation on fruit growth and reserve accumulation in young 'Fuyu' trees. Acta Hortic. 601:99-104.

9. Cline, W. O. 2002. Blueberry bud set and yield following the use of fungicides for leaf spot control in North Carolina. Acta Hortic. 574:7174.

10. Conover, W. J. 1999. Practical Nonparametric Statistics, 3rd ed. Wiley, New York.

11. Danielsen, S., and Munk, L. 2004. Evaluation of disease assessment methods in quinoa for their ability to predict yield loss caused by downy mildew. Crop Prot. 23:219-228.

12. Darnell, R. L. 1991. Photoperiod, carbon partitioning, and reproductive development in rabbiteye blueberry. J. Am. Soc. Hortic. Sci. 116:856-860.

13. Evanylo, G. K., and Sumner, M. E. 1987. Utilization of the boundary line approach in the development of soil nutrient norms for soyabean production. Commun. Soil Sci. Plant Anal. 18:1379-1401.

14. Furman, L. A., Lalancette, N., and White, J. F., Jr. 2003. Peach rusty spot epidemics: Management with fungicide, effect on fruit growth, and the incidence-lesion density relationship. 
Plant Dis. 87:1477-1486.

15. Gough, R. E. 1994. The Highbush Blueberry and Its Management. Haworth Press, Binghamton, NY.

16. Hidalgo, H., Sutton, T. B., and Arauz, F. 1997. Epidemiology and control of citrus greasy spot on Valencia orange in the humid tropics of Costa Rica. Plant Dis. 81:1015-1022.

17. Layne, D. R., and Flore, J. A. 1993. Physiological responses of Prunus cerasus to wholeplant source manipulation: Leaf gas exchange, chlorophyll fluorescence, water relations and carbohydrate concentrations. Physiol. Plant. 88:44-51.

18. Lyrene, P. M. 1992. Early defoliation reduces flower bud counts on rabbiteye blueberry. HortScience 27:783-785.

19. McGovern, R. J., Wilson, A. E., Rouse, R. E., and Welch, A. W., Jr. 2003. Reduction of defoliation in citrus caused by Mycosphaerella citri with a novel biocompatible fungicide. Plant Dis. 87:134-138.

20. Milholland, R. D. 1995. Septoria leaf spot and stem canker. Page 16 in: Compendium of Blueberry and Cranberry Diseases. F. L. Caruso and D. C. Ramsdell, eds. American Phytopathological Society, St. Paul, MN.

21. Ojiambo, P. S., and Scherm, H. 2005. Survival analysis of time to defoliation of blueberry leaves affected by Septoria leaf spot. Phytopa- thology 95:108-113.

22. Ojiambo, P. S., and Scherm, H. 2005. Temporal progress of Septoria leaf spot on rabbiteye blueberry (Vaccinium ashei). Plant Dis. 89:1090-1096.

23. Oliveira, C. M., and Priestly, A. 1988. Carbohydrate reserves in deciduous fruit trees. Hortic. Rev. 10:403-430.

24. Petrie, P. R., Trought, M. C. T., Howell, G. S., and Buchan, G. D. 2003. The effect of leaf removal and canopy height on whole-vine gas exchange and fruit development of Vitis vinifera L. Sauvignon Blanc. Funct. Plant Biol. 30:711-717.

25. Roberts, E. H. 1999. A search for pattern and form. Seed Sci. Res. 9:181-208.

26. Roloff, I., Scherm, H., and van Iersel, M. W. 2004. Photosynthesis of blueberry leaves as affected by Septoria leaf spot and abiotic leaf damage. Plant Dis. 88:397-401.

27. Rosenberger, D. A., Engle, C. A., and Meyer, F. W. 1996. Effect of management practices and fungicides on sooty blotch and flyspeck disease and productivity of Liberty apples. Plant Dis. 80:798-803.

28. Scherm, H., Brannen, P. M., Ojiambo, P. S., Savelle, A. T., Krewer, G., and Bruorton, M. D. 2003. Blueberry leaf spots: Epidemiology, yield losses, and control. Pages 57-66 in: Proc. Southeast. Blueberry Conf. Savannah, GA.
29. Scherm, H., and Krewer, G. 2003. Blueberry production in Georgia: Historical overview and recent trends. Small Fruits Rev. 2:83-91.

30. Sharma, I. M., and Bhardwaj, S. S. 2003. Efficacy and economics of different fungicide spray schedules in controlling premature defoliation disease in apple. Plant Dis. Res. 18:2124.

31. Stokes, M. E., Davis, C. S., and Koch, G. G. 1995. Categorical Data Analysis Using the SAS System. SAS Institute, Cary, NC.

32. Sztejnberg, A. 1986. Etiology and control of cherry leaf spot disease in Israel caused by Cercospora circumscissa. Plant Dis. 70:349351.

33. Teng, P. S. 1987. Quantifying the relationship between disease intensity and yield loss. Pages 05-113 in: Crop Loss Assessment and Pest Management. P. S. Teng, ed. American Phytopathological Society, St. Paul, MN.

34. Titus, J. S., and Kang, S. M. 1981. Nitrogen metabolism, translocation and recycling in apple trees. Hortic. Rev. 4:204-246.

35. Waggoner, P. E., and Berger, R. D. 1987. Defoliation, disease and growth. Phytopathology 77:393-398.

36. Williamson, J. G., and Miller, E. P. 2002. Early and mid-fall defoliation reduces flower bud number and yield of southern highbush blueberry. HortTechnology 12:214-216. 